\title{
Formation of Kinship Terms in Boro
}

\author{
Swarna Prabha Chainary \\ Gauhati University, Assam, India
}

\begin{abstract}
The target of this paper is to introduce a language of the Tibeto-Burman group having its concentration basically in Assam. The Boro language, a language still unknown to most of the parts of the country and to the world, has a different type of structure in its kinship term and this language's peculiarity in some points of kinship formation is highly acknowledgeable and worth discussing. The discussion of this paper will mainly be based on the structure of the kinship terms and its varieties found in the language. These language speakers have their concentrations among the Aryan speakers in Assam and are highly bilingual but this bilingualism has not influenced them in most of the fronts of kinship formations and still they are keeping intact their originality. So, through the discussion of eight major points of kinship formation process an attempt has been made to show its uniqueness which the language has inherited from its parent group.
\end{abstract}

Keywords: bound base, personal pronouns, combination, direct blood relationship, non direct blood relationship

\section{Introduction}

Kinship terms occupy an important place in the lexical composition of the Boro language. The structure of these kinship terms is very much common to various cognate languages of Boro spreading in different North-Eastern States of India and neighboring Nepal. In most of the Tibeto-Burman languages of the region, kinship terms are basically formed with the combination of the singular forms of the personal pronouns but never with the plural forms and the honorific forms of the personal pronouns if a language has (most of the Tibeto-Burman languages have not the use of honorific forms). The formation of kinship terms in Boro language may be discussed under the heads: (1) bound base form of the kinship terms; (2) personal pronoun and bound base; (3) absence of 1st person personal pronoun; (4) combination of bound base and verb; (5) combination of personal pronoun and verb; (6) combination of personal pronoun and noun/adjective; (7) combination of personal pronoun, bound base and noun/adjective; and (8) common kinship terms.

\section{Bound Base Form of the Kinship Terms}

The first process to be mentioned here is the bound base form of the kinship terms. The bound base form of the kinship terms has no own existence in the language to represent independent meanings. But despite that, it functions as the head of the kinship terms, because without it no kinship terms can be formed in the language. These terms are $-\mathrm{p}^{\mathrm{h}} \mathrm{a}, \mathrm{ma}, \mathrm{da}, \mathrm{b}$, , bui, buu, and others and their meanings are to be understood as father, mother, elder brother, elder sister, grandmother, and grandfather without representing my, your, or his/her concept. Though they are considered to have meanings but are never used in isolation without the combination of singular forms of the personal pronouns, i.e., though they have meanings their meanings

Swarna Prabha Chainary, associate professor, Department of Bodo, Gauhati University. 
always need the help of the personal pronouns and so these have been identified as bound base forms of the kinship terms.

\section{Personal Pronouns and Bound Base}

The bound base of the kinship terms is always accompanied by the singular forms of the personal pronouns in the language and is never used with the plural forms. In Boro language, the 1st person singular has only one form but the 2nd and 3rd persons have two different forms, i.e., the non-honorific and honorific. Non-honorific forms in the language are num (you) and bi (he/she), the 2nd and 3rd persons respectively. On the other hand, $-t^{\mathrm{h}}$ an representing honorific sense is added to these two forms of the personal pronouns to form

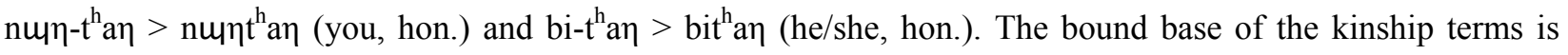
never used with these two forms of the singular personal pronouns in the language, e.g., they are never used as

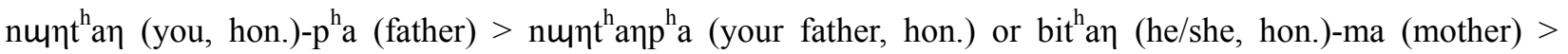
bit ${ }^{\mathrm{h}}$ anma (his/her mother, hon.), etc.

As the combinations shown with the honorific forms of the 2nd and 3rd persons of personal pronouns are invalid combinations, the valid combinations of the bound base of kinship terms accompanied by personal

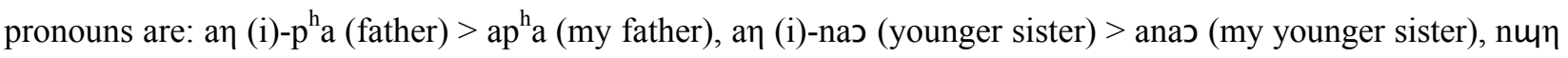
(you, sing.)-bui (grandmother) > nuүbui/numbui (your grandmother), nщү (you, sing.)-da (elder brother) > nuүda (your elder brother), bi (he/she)-bazui (sister-in-law) > bibazui (his/her sister-in-law), bi (he/she)-ma (mother) $>$ bima (his/her mother) etc.

In the above examples, during the addition of the personal pronouns and the bound base of the kinship terms, some oblique forms are taking place in some words and in some 1st person singular a $($ i) when added to the bound base are automatically dropping the last phoneme $/ \eta /$, and only the first vowel phoneme /a/ has been seen added to the bound base of the kinship terms. Like this, the 2nd person when added to the bound base of the kinship terms is sometimes keeping its form intact and sometimes the last phoneme i.e., the velar nasal $/ \eta /$ has been seen replaced by the bilabial nasal $/ \mathrm{m} /$. When a kinship term begins with bilabial plosive/stop sounds without keeping any differences of voiceless or voiced and the bilabial nasal sound then the last velar nasal sound $/ \eta /$ of the second person singular (non-hon.) turns to the bilabial nasal $/ \mathrm{m} /$ and when the bound base of the kinship terms begins with the sounds other than these two then the 2nd person non-honorific form of the personal pronoun remains in intact position, e.g., nuү (you)-sa (child)-zu (female) > nuүsazu (your daughter), nщү (you)-haว (father-in-law) > nuүhaว (your father-in-law), etc.. In these two examples, the first example is being started with the voiceless alveolar fricative /s/, and the second example is started with the voiceless glottal fricative $/ \mathrm{h} /$. So, in these two examples, the personal pronoun and the bound base of the kinship terms have been added to each other without any changes. Though it can be established as a rule, in some cases during the addition of the 2nd person non-honorific form of the personal pronoun to the bound base of the kinship terms, some are combined in intact position as per the condition mentioned above and in some combinations assimilations occur. So, two parallel comments can be kept in this case, i.e., when a bound base of the kinship term starts with a bilabial plosive then the velar nasal phoneme $/ \eta$ may either be changed to the bilabial $/ \mathrm{m} /$ due to assimilation or may also be kept intact without any changes, e.g., nuү (you, non-hon)-ma (mother) $>$ nuүma/numma (your mother), nuү (you, non-hon.)-p ${ }^{\mathrm{h}}$ a (father) $>$ nuү $\mathrm{p}^{\mathrm{h}} \mathrm{a} /$ nump $^{\mathrm{h}}$ a. But when the third person (non-hon.) singular form is added to any bound base of the kinship terms then it remains in intact position without keeping any difference of voiced-voiceless or bilabial, alveolar and others. 


\section{Absence of 1st Person Personal Pronoun}

It is not mandatory in case of the Boro language that all bound bases of the kinship terms are to be accompanied by the singular forms of the personal pronoun. There are some kinship terms which though being accompanied by the singular numbers of the $2 \mathrm{nd}$ and 3rd person personal pronouns are never accompanied by 1st person singular form. The examples are -bazui (wife of one's elder brother, without taking the first person form of the personal pronoun); gumui (husband of one's elder sister); biyay (father-in-law of one's son/daughter); biyani (mother-in-law of one's son/daughter); buinay (younger brother of one's wife), səทgra (one's son/daughter's socially recognized father), səクgri (one's son/daughter's socially recognized mother), etc.

The kinship terms mentioned above have represented my sense without the addition of the 1st person form of the personal pronoun an (i). If one goes to these terms through the sociolinguistic point of view then it is to be said that the above mentioned relations have not any blood relation with $i$ (me), i.e., the speaker. The relation of the above kinship terms has been established by the speaker either through the social institution of marriage or the other socially recognized convention known in society as sumund $k^{h}$ anai ${ }^{1}$. So to show its distance from the speaker, i.e., the non-direct blood relationship of these kinship terms has not been attached with the 1st person form of the personal pronoun which is seen using only with one's own, i.e., the very near and dear ones developed from the direct blood relationship. On the other hand, the above kinship terms may be used freely with the other two singular forms of personal pronouns nuү (you) and bi (he/she), e.g., nuy (you)-bazui (sister-in-law) > nщүbazщi/numbazui (your sister-in-law), bi (he/she)-bazmi (sister-in-law) > bibazmi (his/her sister-in-law), nщy (you)-gumщi (brother-in-law) > nuygumщi (your brother-in-law), bi (he/she)-gumui (brother-in-law) > bigumui (his/her brother-in-law), etc.

\section{Combination of Bound Base and Verb}

The number of the kinship terms formed under this process is very minimal. Till date, the author has encountered only one example of such kinship term in the language where the first person singular form of the personal pronoun is not attached to the bound base. Such kinship term in the language is madui i.e., the younger sister of one's mother and its literal meaning is the small mother, own mother being recognized as elder or big because, in the foregone days in the society when a man became widower then to look after his kids or to help him in his agricultural and household activities he remarried the younger sister of his deceased wife if available or the close relative of the same relationship of his wife. Here ma (mother, a bound base as mentioned earlier) and dui > dui (be small), the combination of the two is becoming madui. This same relation is also used to the co-wife of his/her father by the sons/daughters of the first wife. To represent the younger sister of one's mother by the speaker the first person singular number of the personal pronoun is never used and when it is used to represent yours and his/her then it can take the 2nd and 3rd person singular forms of the personal pronoun plus bound base of the kinship term plus verb and may be termed as an extended form of the kinship term madui, e.g., nuү (you)-ma (mother)-dui dui (be small) > nuүmadui/numadui (the younger sister of your mother), bi (he/she)-ma (mother)-dui dui (be small) > bimadui (the younger sister of his/her mother). The non-attachment of the 1st person singular form with the kinship term madui may be explained in the way that there is a preconception that the co-wife (younger one) of one's father always becomes envy to the

\footnotetext{
${ }^{1}$ A kind of social norm where a relation can be established between different sex and age groups by following some rituals and by the articulation of charms by the priest. The relation can be of brother-sister, parents-son/daughter and the like.
} 
sons/daughters of her elder co-wife. This may be the reason that in the society she was never considered as close to the children of the elder co-wife and this very concept was applied even to the younger sister of one's mother as sometimes she also becomes the co-wife (younger) of her elder sister.

\section{Combination of Personal Pronoun and Verb}

The combination of this type of kinship term is also very limited in the language and as mentioned just above under this process also the author has encountered only one such term and is adui (one's father's younger brother/uncle). This term is used to represent uncle in the standard language but in some dialects of the language due to semantic change it represents one's mother's younger sister or one's father's younger brother's wife. This term is composed of one 1st person singular pronoun an(i) and the verb dui (be small) $>$ duil, but when it represents your and his/her father's younger brother this dui is changed to th $\mathrm{t}^{\mathrm{h}} \mathrm{i}$. The term adui represents only mine and when dui $>$ dui is used with the 2nd and 3rd persons then it takes the form of num (you) $-\mathrm{t}^{\mathrm{h}} u \mathrm{i}$ (the $\mathrm{d}$ phoneme of dui $>$ dui changing to the voiceless aspirated $\mathrm{t}^{\mathrm{h}}$ ) $>$ numt ${ }^{\mathrm{h}} u \mathbf{i}$ (your father's younger brother) and bi (he/she)- $t^{\mathrm{h}} u \mathrm{i}>$ bibt $^{\mathrm{h}} u \mathrm{i}$ (his/her father's younger brother). In numt ${ }^{\mathrm{h}} u \mathbf{i}$, i.e., in the 2 nd person the voiced velar nasal $/ \eta /$ has been changed to the voiced bilabial nasal $/ \mathrm{m} /$ because of its having the voiced alveolar $/ \mathrm{d} /$ in the original form and it has no relation with its changing to the voiceless alveolar $/ \mathrm{t}^{\mathrm{h}} /$ as shown in the example. On the other hand, in the term bibt ${ }^{\mathrm{h}} u \mathrm{i}$, a voiced bilabial plosive $/ \mathrm{b} /$ has been inserted in between a pronoun and the bound base. The combination of the personal pronoun and verb and its representation of two different meanings in different dialects of the language seems to be interesting. The term adui which is representing different meanings in dialects (to represent mine) takes separate forms for males

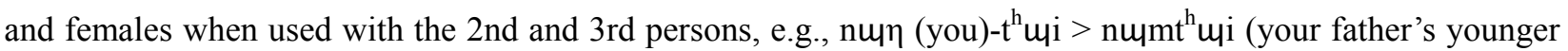
brother) and bi (he/she) - $\mathrm{t}^{\mathrm{h}} u \mathrm{i}>$ bibt $^{\mathrm{h}} \mathrm{il}_{\mathrm{i}}$ (his/her father's younger brother) for males and nuү (you)-ma (mother)-dui dui (be small) > nuฑmadui/numadui (your mother's younger sister), bi (he/she)-ma (mother)-dui dui (be small) > bimadui (his/her mother's younger sister) for females.

\section{Combination of Personal Pronoun and Noun/Adjective}

Kinship term in the Boro language is also formed with the combination of the 1st person singular form and one noun/adjective. The kinship term formed under this structure is only one and the term is anui used to represent wife of one's maternal uncle or the elder or younger sister of one's father. This word is composed of

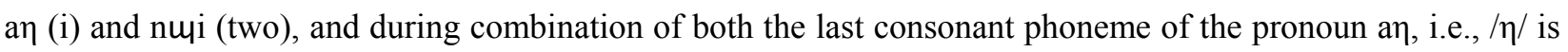
temporarily dropped and the literal meaning of this word is to be represented as "my two", i.e., and another close relative whose status is immediately after the mother in the society. Because in the society there are a lot of children who are taken care of by their anui from early childhood till maturity and they also pay respect to her as their mother.

\section{Combination of Personal Pronoun, Bound Base, and Noun/Adjective}

The one more process of formation of the kinship terms is the combination of the 2 nd and 3 rd person singular personal pronouns with the bound base of the kinship terms and the nouns/adjectives. This kind of kinship term is also not so abundant in the language and is better to discuss from the sociolinguistic point of view. One such term is nщүтаnщi/mumanщi/nummanui (your father's elder or younger sister or your mother's elder or younger brother's wife) and bimanui (his/her father's elder/younger sister or his/her mother's 
elder or younger brother's wife). These kinship terms are composed of nuү (you)-ma (mother)-nui (two/second) > nuүmanui/numanui/nummanui (the literal meaning is your second mother) and bi (she)-ma (mother)-nui (two) > bimanui (literal meaning is his/her second mother). This kinship term has the status and role of the second mother in the society, because in the foregone days (though it is almost extinct in the modern society having nuclear family), the boys and girls were very much attached to their maternal uncle's family or to the family of his/her father's elder or younger sister and in most of the time for their study they selected the family of the maternal uncle and also the family of their father's elder or younger sister. At that time, he/she was to be taken care of by numanui or bimanui of the family as their children. From this concept and the duty and responsibility assigned to them may be this term has developed in the society long years back from today. The other such terms are nunanui and biyanui. The structures of these two kinship terms are also almost similar to the structure of the kinship terms numanui and bimanui. These two kinship terms may be broken as nuү (you, sing.)-ma (mother, temporarily dropping the sound $/ \mathrm{m} /$, because in Boro society age is not a great factor to get the honor or status basically in case of kinship terms)-nui (two) and bi (he/she)-ma (mother)-nui (two) representing the meanings of your niece and his/her niece respectively and in both the examples one personal pronoun, one bound base and one noun/adjective have been added.

\section{Common Kinship Terms}

In Boro society, no different kinship terms are found relating to the male or female lineage. What one calls the parents of his/her father will be the same to the parents of his/her mother, e.g., abuu (maternal or paternal grandfather) and abui (maternal or paternal grandmother). On the other hand, the terms for the elder brother of one's father and the elder sister of one's mother are also the same. When a speaker addresses both of them it

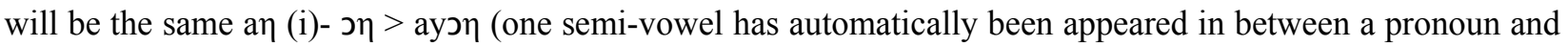
a bound base of kinship term temporality dropping the last consonant phoneme of the pronoun ) and during

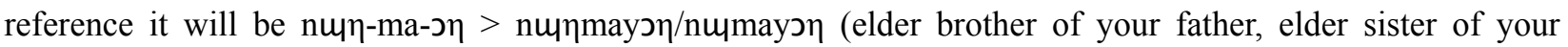

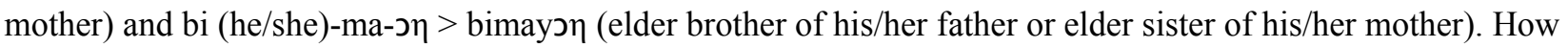
the bound form ma representing mother or female has been used to represent both the genders in the language is interesting, and it represents the preference and status given to the women in the society. When one is to differentiate between the male and female then the attributes huua and hinzas representing respectively male and female are to be used after the term ayว $\eta$, and in case of the 2nd and 3rd persons these two terms representing male and female may either be preceded or followed though the most accepted norm is the following of the noun. On the other hand, there is no concept of cousin brother or cousin sister in the language and all are considered and addressed as siblings of the same parents and what one addresses to his/her own siblings he/she will address in the same way to the siblings of his/her father's siblings' and mother's siblings' sons and daughters. On the other hand, in the traditional village society, all the villagers use different terms of address and references to each other based on the age and social status.

\section{Conclusions}

(1) Generally, the kinship terms of the Boro language cannot exist in its own without the help of the singular forms of the personal pronouns (not the honorific form of personal pronouns), so the terms like father, mother, and others used in English have no relevance in Boro language; 
(2) The kinship terms which have no paternal or maternal lineage with the speaker generally do not take the 1 st person forms of the singular personal pronoun though they can take the 2 nd and the 3rd persons along with them;

(3) Some exceptions are also seen to the comment mentioned in case of the term madui. The reason may be that it represents two relations, one is used to represent the younger sister of one's mother and the other one is used to represent the step mother called bihari/biharui in Boro which has also the meaning of "enemy" besides co-wife (the 2 nd wife is thought to be the enemy of the 1st wife because of sharing her everything) in the language. May be this is the reason that to generalize these two terms the first person form of the personal pronoun has not been attached to it though the 2nd and 3rd persons are seen using;

(4) The Boros give equal value and status to the relatives of the mother and father and that is the reason that there are no different terms to represent the parents of mother and father, the maternal uncles and their wives, and also father's elder and younger sisters and their husbands;

And (5) The elder brother of one's father and the elder sister of one's mother share the same term without keeping any difference of sex in the society. When it is to be specified then only the male and female representing terms like huua (male) and hinzas (female) are to be used before or after the common kinship term though the most regular one is using after the noun.

\section{References}

Basumatry, P. (2005). An introduction to the Boro language. New Delhi: Mittal Publications. Benedict, P. K. (1972). Sino-Tibetan a conspectus. Cambridge: Cambridge University Press.

Burling, R. (2004). The language of the Modhupur Mandi (Garo), Vol. 1: Grammar. New Delhi; New Jersey: Bibliophile South Asia in Association with Promilla \& Co. Publishers.

Chainary, S. P. (2006). Boro grammar (Boro Raokhanthi). Guwahati: Gumur Publications.

Dhar, P. C. (Ed.). (1987). Kak-Kuthumma. Agartala: Tribal Research Institute.

Marak, H. W. (2000). Ku bidik. (2nd ed.). Guwahati: Assam Academy for Cultural Relations.

Narzary, S. (Ed.). (2006). Bodo-English-Hindi dictionary. Kokrajhar: Bodo Sahitya Sabha. 